\title{
Efeitos do flavonóide quercetina e dos corantes bixina e norbixina sobre parâmetros sanguíneos de coelhos
}

\section{Effects of the flavonoid quercetin and the natural dyes bixin and norbixin on blood parameters of rabbits}

Leonardo Ramos Paes LIMA ${ }^{1}$

Tânia Toledo de OLIVEIRA ${ }^{1}$

Tanus Jorge NAGEM ${ }^{2}$

\section{R E S U M O}

Avaliou-se a ação terapêutica da quercetina, bixina e norbixina, na dose diária de $0,01 \mathrm{~mol} / \mathrm{kg}$, em coelhos hiperlipidêmicos induzidos por colesterol a $0,5 \%$ e ácido cólico a $0,1 \%$, durante o período de vinte e oito dias, após o qual foram dosados colesterol, colesterol-HDL, triacilgliceróis, uréia, creatinina, ácido úrico, proteínas totais, cálcio, aspartato aminotransferase e alanina aminotransferase. Estes estudos são importante para se verificarem os efeitos de flavonóides e corantes sobre o metabolismo destas substâncias, permitindo a interpretação de desordens hepáticas ou renais. Os resultados mostraram que os teores de colesterol foram menores para os animais tratados com bixina $(-4,03 \%)$ e quercetina $(-35,07 \%)$, enquanto sua associação reduziu o nível de uréia em $5,73 \%$. Nenhuma das substâncias testadas apresentou efeitos deletérios, todavia, não é possível demonstrar a inocuidade destes compostos.

Termos de indexação: quercetina, bixina, norbixina, metabolismo, coelhos da raça Nova Zelândia, colesterol, lipoproteínas do colesterol-HDL, uréia, flavonas.

\section{A B S T R A C T}

The objective of this study was to evaluate the therapeutic action of quercetin, bixin and norbixin, in the daily dose of $0,01 \mathrm{~mol} / \mathrm{kg}$, in hyperlipidemic rabbits induced by cholesterol at $0.5 \%$ and colic acid at $0.1 \%$, during

1 Departamento de Bioquímica e Biologia Molecular, Universidade Federal de Viçosa. Av. P.H.Rolfs, s/n, 36571-000, Viçosa, MG, Brasil. Correspondência para/Correspondenceto: L.R.P. LIMA. E-mail: Ilima@buynet.com.br

2 Departamento de Química-Universidade Federal de Ouro Preto, Campus M orro do Cruzeiro, 35400-000, Ouro Preto, MG, Brasil. 
the period of twenty-eight days, after which they were anesthetized and samples of blood were collected, in order to determine cholesterol, HDL-cholesterol, triacylglycerols, urea, creatinine, uric acid, total proteins, calcium, aspartate aminotransferase and alanine aminotransferase. These researchs are important to verify the effects of flavonoids and natural dyes on the metabolism of these constituents, in order to study hepatic or renal disorders. The results showed that cholesterol was reduced by bixin $(-44.03 \%)$ and by quercetin $(-35.07 \%)$, while the association reduced urea in $5.73 \%$. None of the constituents analyzed in this study presented deleterious effects and it was not possible to demonstrate the innocuity of these compounds.

Index terms: quercetin, bixin, norbixin, metabolism, New Zealand rabbits, cholesterol, lipoproteins, HDL-cholesterol, urea, favones.

\section{N T R O D U Ç Ã O}

A avaliação toxicológica é realizada com ensaios biológicos em animais e os resultados são extrapolados para humanos, o que muitas vezes é difícil, pois os resultados podem variar muito entre espécies. Nestes casos, os exames hematológicos e bioquímicos, a autópsia geral, a histopatologia e o acompanhamento dos efeitos mutagênicos, teratogênicos e carcinogênicos e a manutenção do grupo controle para fins de comparação devem ser realizados, bem como a avaliação do estado geral dos animais, durante 0 tempo transcorrido até a morte de $50 \%$ dos mesmos, além da observação dos ef eitos tóxicos.

Segundo estabeleceram vários ensaios clínicos, a diminuição dos níveis de colesterol em homens saudáveis de meia idade, sem doença cardíaca coronária (prevenção primária), reduz seu risco e esta redução do risco é proporcional à diminuição do colesterol-LDL e ao aumento do colesterol-HDL. Indivíduos nos grupos de tratamento tiveram reduções estatisticamente significantes e clinicamente importantes das taxas de infartos do miocárdio, de novos casos de angina e de necessidade de cirurgias de revascularização miocárdica. Em indivíduos que já têm doença coronária, os benefícios da redução do colesterol (prevenção secundária) são mais claros, com reduções na progressão da aterosclerose coronária, menor número de eventos coronários subseqüentes, menor mortalidade por doença cardíaca coronária e uma diminuição na mortalidade por todas as causas. Nestes casos, a prevenção secundária desempenharia um papel mais expressivo, pois seria necessária a intervenção de um menor número de indivíduos em comparação com a prevenção primária, o que, em termos econômicos, seria menos dispendioso. Conforme alguns estudos ${ }^{1}$ também demonstraram que a redução agressiva dos níveis de colesterol leva à regressão de placas ateroscleróticas em alguns indivíduos, reduz a progressão da aterosclerose em enxertos de veia safena e pode retardar ou reverter a aterosclerose das carótidas. Uma análise recente sugere que este último efeito resulta em uma diminuição significativa dos acidentes vasculares cerebrais.

Os efeitos protetores da quercetina na redução da toxidade da cisplatina em cultura de células epiteliais tubulares renais foi mostrado por Kuhlman et al. (1998)². Este antineoplásico tem a propriedade de se acumular nas células do tubo proximal, causando tubulotoxidade, perda de microvilosidades, alterações no número de lisossomos, vacuolização e outros danos da mitocôndria, além de inibir a síntese protéica e a glutationa e causar a peroxidação lipídica. Nesta pesquisa, a catequina, silibina, rutina e quercetina mostraram-se eficazes em proteger as células do túbulo renal por suas propriedades antioxidantes, reduzindo a nefrotoxidade em $30 \%$ a $50 \%$.

Relatos da literatura demonstram os efeitos não tóxicos de flavonóides e sua ação na redução da vulnerabilidade do endotélio microvascular a inflamações e estresse oxidativo. As antocianinas podem atuar como antioxidantes em espécies reativas de oxigênio geradas por neutrófilos e 
monócitos, resistindo aos efeitos tóxicos gerados por essas espécies. Um possível processo com as espécies reativas de oxigênio pode explicar os efeitos deletérios que são ativados por monócitos e neutrófilos. Os mecanismos moleculares envolvidos no recrutamento via ações de diferentes quimioatraentes secretados por células endoteliais parecem depender de complexos processos. Isto inclui uma alteração no estado redox das células em resposta a processos inflamatórios, fatores de necrose tumoral e processos isquêmicos. As células endoteliais ativadas aumentam a expressão de citoquinas, quimoquinas, neutrófilos, monócitos quimioatraentes, sítios de inflamação e adesão de moléculas. 0 acúmulo localizado de leucócitos e a subseqüente adesão do endotélio vascular acrescidos dos altos níveis de colesterol na íntima arterial, têm um papel na aterogênese bem como na ruptura das plaquetas em lesões aterogênicas avançadas 3 .

Os flavonóides com o grupo hidroxila no anel-B são eficientes inibidores da glicação do colágeno, uma das vias que podem desencadear o processo ateromatoso, por haver liberação de radicais livres. Em reações de glicação de carboidratos estes produtos podem provocar a oxidação da lipoproteína de baixa densidade (LDL). Esta, quando oxidada, danifica o endotélio. É importante lembrar ainda que em diabéticos formam-se várias ligações cruzadas entre colágeno e açúcares. Uma relação similar é observada com os metabólitos dos flavonóides. A inibição da glicação pode ser resultante da ligação do grupo amino ao flavonóide ${ }^{4}$.

Luna et al. (1996) $)^{5}$ demonstraram que os compostos fenólicos possuem atividade antiviral contra o vírus da imunodeficiência em humanos, herpes simples e pólio. Ainda de acordo com estes autores, flavonóides como a quercetina induzem um aumento do crescimento celular, diminuindo a peroxidação de lipídeos em nível de membrana e outros flavonóides podem inibir a proliferação celular.

M ascolo et al. (1998) ${ }^{6}$ relataram testes com os flavonóides quercetina, kaempferol e taninos, nos quais eles apresentaram com atividade antiinflamatória, atuaram como inibidores de enzimas lisossômicas e foram responsáveis por aumentar a filtração transcapilar de água e proteínas, reduzindo o número e o diâmetro de poros capilares e promovendo o retorno do fluxo sanguíneo para o coração.

Estima-se que os humanos ingerem menos de $100 \mathrm{mg} /$ dia destes compostos na dieta. Os flavonóides presentes em alimentos são absorvidos mesmo com a presença de um grupo glicosil. Já se sabe que a quercetina glicosilada, a mais difundida nos alimentos, pode ser absorvida em maior escala que a quercetina aglicona. A hidrólise dos flavonóides no intestino delgado é efetuada por microorganismos, não sendo enzimática ${ }^{7}$.

M uitos estudos têm sido conduzidos com esta classe de flavonóides, e as flavonas, tais como a quercetina e luteolina, têm mostrado efeitos como antioxidantes na prevenção de câncer e também como inibidores na formação de placas ateroscleróticas. Cai et al. (1999) demonstraram os efeitos da quercetina e luteolina na remoção dos radicais superóxidos, na inibição da formação de radicais livres, principalmente $\mathrm{O}_{2}$ e na inibição da oxidação lipídica induzida por $\mathrm{FeCl}_{2}$ no fígado de ratos.

Os autores deste artigo têm desenvolvido trabalhos em laboratórios utilizando modelos animais para hipercolesterolemia, diabetes, osteoporose, ações antiulcerativas e outros fins, analisando os efeitos de flavonóides, corantes naturais e fármacos. Em um desses estudos, Lima et al. (2001) desenvolveram pesquisas com bixina, norbixina e quercetina e avaliaram seus efeitos no metabolismo lipídico de coelhos. A bixina apresentou o maior valor na redução do colesterol total. Com relação à concentração de triacilgliceróis, a quercetina obteve a maior percentagem de redução e a associação bixina + quercetina demonstrou uma percentagem de redução de $-38,92 \%$, valor maior que o da bixina isoladamente. Pesquisas avaliando corantes naturais e flavonóides também foram realizadas por Oliveira et al. $(2001)^{10}$, os quais testaram a 
naringina e o corante monascus isoladamente e associados. A associação destes reduziu as concentrações de colesterol em $66,70 \%$, aumentou a lipoproteína de alta densidade (HDL) em $16,14 \%$ e diminuiu os triacilgliceróis em $63,33 \%$.

A literatura relata ainda que os carotenóides apresentam efeito antioxidante, sendo de importância na prevenção da aterosclerose. A lipoproteína $L D L$, quando oxidada, danifica 0 endotélio e, por conseguinte, a ação antioxidante dos carotenóides, entre os quais se incluem a bixina e a norbixina, protegeria o endotélio dos danos desta lipoproteína. As lesões ateroscleróticas iniciam-se após algum tipo de injúria ao endotélio normalmente causada pela LDL oxidada. Os carotenóides são captados neste processo e impedem esta oxidação ${ }^{11}$. Assim, considerando que estas substâncias possam ser viabilizadas, no futuro, como medicamentos no controle do metabolismo lipídico, testes toxicológicos tornam-se necessários.

Dessa forma, o presente trabalho foi instituído com o objetivo de avaliar a toxicidade aguda por doses repetidas, durante 28 dias, dos corantes naturais bixina e norbixina e do flavonóide quercetina em coelhos hiperlipidêmicos tratados diariamente com colesterol e ácido cólico, por via oral, para analisar os efeitos das substâncias sobre os parâmetros sangüíneos.

\section{MATERIALE MÉTODOS}

Utilizaram-se coelhos da raça Nova Zelândia, com peso médio de $1550 \pm 100 \mathrm{~g}$ no início do experimento e com idade de oito semanas, chegando a $2200 \pm 100 \mathrm{~g}$ após atingir doze semanas de idade.

Eles receberam a ração comercial Nutricoelhos ${ }^{\circledR}$ na proporção de 100 gramas diárias e água à vontade.

Os coelhos foram separados em seis grupos contendo seis animais cada um, distribuídos ao acaso, com os seguintes tratamentos: Grupo 1
(G1) - Ração; Grupo 2 (G2) - Ração + colesterol + ácido cólico; Grupo 3 (G3) - Ração + colesterol + ácido cólico + bixina; Grupo 4 (G4) - Ração + colesterol + ácido cólico + quercetina; Grupo 5 (G5) - Ração + colesterol + ácido cólico + bixina + quercetina; Grupo 6 (G6) - Ração + colesterol + ácido cólico + norbixina.

A hiperlipidemia foi induzida administrando-se, por via oral, colesterol a 0,5\% e ácido cólico a $0,1 \%$ em relação ao peso da ração diária. 0 colesterol e o ácido cólico foram ministrados todos os dias, juntamente com a ração e as substâncias a serem testadas.

As substâncias-teste foram fornecidas na dose de $0,01 \mathrm{~mol} / \mathrm{kg}$ de peso corporal, por via oral, em cápsulas, utilizando talco como veículo. Os animais dos grupos 1 e 2 também receberam as mesmas cápsulas, mas sem as substâncias-teste.

No tempo zero e após 28 dias de tratamento, as amostras do sangue foram coletadas e centrifugadas a $7100 \times \mathrm{g}$ durante 15 minutos, para obtenção dos soros. As dosagens sorológicas foram efetuadas e os resultados obtidos foram expressos em $\mathrm{mg} / \mathrm{dL}$ de colesterol total, colesterol-HDL, triacilglicerol, creatinina, proteínas totais, cálcio, uréia e ácido úrico e em UI para alanina amino-transferase (ALT) e aspartato aminotransferase (AST), utilizando-se Kits da marca Biolab ${ }^{\circledR}$ e o equipamento Alizé ${ }^{\circledR}$ (analisador automático de Bioquímica).

0 delineamento experimental foi inteiramente ao acaso, com seis tratamentos em seis repetições. Usou-se o teste de Tukey, o qual faz contrastes não ortogonais de comparação entre duas médias e permite estabelecer a diferença mínima significante, ou seja, a menor diferença de médias de amostras que deve ser tomada como estatisticamente significativa em determinado nível. Empregou-se também o teste de Dunnett, o qual utiliza contrastes não ortogonais, compara cada média apenas com a testemunha e é feito quando as únicas comparações que interessam ao experimentador são aquelas realizadas entre um determinado 
tratamento padrão, geralmente a testemunha, e cada um dos demais tratamentos, não havendo interesse na comparação dos demais tratamentos entre si.

\section{RESULTADOSE DISCUSSÃ O}

Foram calculadas as médias e as percentagens de variação relativas aos níveis de colesterol total, colesterol-HDL, triacilglicerol, uréia, creatinina, ácido úrico, proteínas totais, cálcio e enzimas AST e ALT. Estes dados foram avaliados no soro dos coelhos hiperlipidêmicos, que receberam as substâncias bixina, quercetina e norbixina isoladamente e a associação de bixina com quercetina, comparando-se os resultados após 28 dias de tratamento com os níveis dos grupos controles $G_{1}$ (Ração) e $G_{2}$ (Ração + colesterol +ácido cólico).

Os teores de colesterol foram menores para os animais tratados com bixina $(-44,03 \%)$, e a quercetina isoladamente apresentou também uma excelente percentagem de redução $(-35,07 \%)$ (Tabela 1).

Tabela 1. Colesterol total, Colesterol-HDL e triacilgliceróis (terro-padrão) de coelhos avaliados aos 28 dias.

\begin{tabular}{|c|c|c|c|}
\hline \multirow{2}{*}{ Grupos } & \multirow{2}{*}{ Colesterol (mg/dL) } & \multicolumn{2}{|c|}{ \% de variação em relação a } \\
\hline & & Ração & Ração + CAC \\
\hline 1 - Ração (R) & $138,33 \pm 17,87$ & - & - \\
\hline $2-\mathrm{R}+$ Colesterol + Ácido cólico (CAC) & $1590,40 \pm 136,75$ & - & - \\
\hline $3-C A C+$ bixina & $890,20 \pm 144,83 b$ & $543,53^{*}$ & $-44,03 *$ \\
\hline $4-$ CAC + quercetina & $1032,67 \pm 59,84 a b$ & $646,53 *$ & $-35,07 *$ \\
\hline $5-C A C+$ bixina + quercetina & $1433,40 \pm 119,20 a$ & $936,22 *$ & $-9,87$ \\
\hline \multirow[t]{2}{*}{$6-C A C+$ norbixina } & $1187,26 \pm 195,54 a b$ & $758,28 *$ & $-25,35^{*}$ \\
\hline & \multirow{2}{*}{ Colesterol-HDL (mg/dL) } & \multicolumn{2}{|c|}{ \% de variação em relação a } \\
\hline Grupos & & Ração & Ração + CAC \\
\hline 1 - Ração (R) & $47,96 \pm 2,96$ & - & - \\
\hline $2-\mathrm{R}+$ Colesterol + Ácido cólico (CAC) & $155,17 \pm 9,93$ & - & - \\
\hline 3 - CAC + bixina & $137,43 \pm 8,71 a$ & $186,55^{*}$ & $-11,43$ \\
\hline $4-$ CAC + quercetina & $134,51 \pm 3,83 a$ & $180,46 *$ & $-13,31$ \\
\hline $5-$ CAC + bixina + quercetina & $133,77 \pm 17,01 a$ & $178,92 *$ & $-13,79$ \\
\hline \multirow[t]{2}{*}{$6-\mathrm{CAC}+$ norbixina } & $131,55 \pm 21,84 a$ & $174,29 *$ & $-15,22$ \\
\hline & \multirow{2}{*}{ Triacilgliceróis (mg/dL) } & \multicolumn{2}{|c|}{ \% de variação em relação a } \\
\hline Grupos & & Ração & Ração + CAC \\
\hline 1 - Ração (R) & $113,78 \pm 19,52$ & - & - \\
\hline 2 - R + Colesterol + Ácido cólico (CAC) & $266,72 \pm 60,96$ & - & - \\
\hline 3 - CAC + bixina & $228,79 \pm 29,21 a b$ & $101,08 *$ & $-14,22$ \\
\hline 4 - CAC + quercetina & $153,30 \pm 8,73 a$ & 34,73 & $-42,52 *$ \\
\hline 5 - CAC + bixina + quercetina & $162,90 \pm 16,66 b$ & 43,17 & $-38,92 *$ \\
\hline $6-\mathrm{CAC}+$ norbixina & $292,32 \pm 25,22 a$ & $156,92 *$ & 9,60 \\
\hline
\end{tabular}

M édias seguidas de mesma letra minúscula não diferem entre si pelo teste de Tukey $(p>0,05)$.

${ }^{(*)}$ Estatisticamente diferente dos grupos controle pelo teste de Dunnett $(p<0,05)$.

DMS Dunnett $=306,48 \mathrm{mg} / \mathrm{dL}$ (Colesterol).

DMS Dunnett $=37,25 \mathrm{mg} / \mathrm{dL}$ (Colesterol-HDL),

DMS Dunnett $=77,51 \mathrm{mg} / \mathrm{dL}$ (triacilgliceróis). 
Zhao et al. (1998) ${ }^{12}$ relatam o efeito de carotenóides ( $\beta$-caroteno, luteína, bixina e cataxantina) na ruptura da respiração em macrófagos peritoneais, atuando como antioxidante durante estes processos. Os principais radicais formados seriam de oxigênio, água oxigenada, hidroxila, óxido nitroso e óxido nítrico. Quando isto ocorre, o colesterol se deposita no interior das artérias e os macrófagos ou células em espuma também migram para estas regiões. A geração de radicais livres é bastante prejudicial, pois eles oxidam a LDL, levando à danificação do endotélio. Esta ação antioxidante dos carotenóides é de extrema importância na prevenção da aterosclerose.

De acordo com mecanismos de ação de flavonóides, os efeitos hipolipidêmicos associados a interações destas substâncias com biomembranas permitem que esta classe de compostos possa interagir nas bicamadas lipídicas das membranas, alterando suas barreiras. Estes efeitos explicam diversos fatores, como conformação e hidrossolubilidade de fármacos. Os flavonóides, alterando a permeabilidade das membranas celulares, podem ser um fator crítico na explicação de muitas de suas atividades biológicas. A ação antibacteriana de catequinas, por exemplo, é associada à sua capacidade de danificar a bicamada lipídica em bactérias. Esta ação é importante em aterosclerose, onde, além do depósito do colesterol em excesso nas artérias, também ocorre uma infecção provocada por bactérias ${ }^{13}$.

Em relação aos níveis de colesterol-HDL plasmático (Tabela 1), a bixina foi a que menos reduziu sua concentração. Isto é uma vantagem, pois o colesterol-HDL transporta o colesterol da circulação para o fígado, onde ele é metabolizado.

Quanto aos triacilgliceróis plasmáticos (Tabela 1), a quercetina foi a mais eficaz na redução dos seus níveis. Como a lipase é a enzima que hidrolisa os triacilgliceróis, estes resultados parecem muito promissores, pois relatos na literatura (Lima et al., 1999)14 identificaram a rutina e naringina como os flavonóides que mais aumentaram a atividade da lipase, em uma percentagem de $74,28 \%$ e $124,77 \%$, respectivamente, quando comparados com outros flavonóides. Estas substâncias podem atuar reduzindo a hipercolesterolemia e hipertrigliceridemia em animais e, no futuro, em humanos.

No tocante aos constituintes sangüíneos, a associação bixina + quercetina reduziu o nível de uréia (Tabela 2) em 5,73\% em relação ao tratamento com ração, colesterol e ácido cólico; no entanto, esta redução não é estatisticamente diferente pelo teste de Dunnett e não difere dos outros grupos pelo teste de Tukey. Comparado com o grupo que recebeu apenas ração, a redução foi de $33,99 \%$, sendo esta estatisticamente significativa pelo teste de Dunnett.

Tabela 2. Uréia e Creatinina ( $₫$ erro-padrão) de coelhos avaliados aos 28 dias.

\begin{tabular}{|c|c|c|c|c|c|c|}
\hline \multirow{2}{*}{ Grupos } & \multirow{2}{*}{ Uréia (mg/dL) } & \multicolumn{2}{|c|}{ \% de variação } & \multirow{2}{*}{ Creatinina $(\mathrm{mg} / \mathrm{dL})$} & \multicolumn{2}{|c|}{ \% de variação } \\
\hline & & Ração & Ração + CAC & & Ração & Ração + CAC \\
\hline 1 - Ração (R) & $38,60 \pm 1,55$ & - & - & $1,17 \pm 0,05$ & - & - \\
\hline $2-\mathrm{R}+$ Colesterol + Ácido cólico (CAC) & $27,03 \pm 1,06$ & - & - & $1,32 \pm 0,06$ & - & - \\
\hline $3-\mathrm{CAC}+$ bixina & $26,70 \pm 1,54 a$ & $-30,83^{*}$ & $-1,22$ & $1,15 \pm 0,08 a$ & $-1,71$ & $-12,88 *$ \\
\hline $4-C A C+$ quercetina & $25,84 \pm 1,30 a$ & $-33,06 *$ & $-4,40$ & $1,36 \pm 0,04 a$ & $16,24 *$ & 3,03 \\
\hline $5-C A C+$ bixina + quercetina & $25,48 \pm 0,85 a$ & $-33,99 *$ & $-5,73$ & $1,19 \pm 0,02 a$ & 1,71 & $-9,85$ \\
\hline $6-C A C+$ norbixina & $26,77 \pm 1,48 a$ & $-30,65 *$ & $-0,96$ & $1,28 \pm 0,03 a$ & 9,40 & $-3,03$ \\
\hline
\end{tabular}

Médias seguidas de mesma letra minúscula não diferem entre si pelo teste de Tukey $(p>0,05)$.

${ }^{(*)}$ Estatisticamente diferente dos grupos controle pelo teste de Dunnett $(p<0,05)$.

DMS Dunnett $=3,52 \mathrm{mg} / \mathrm{dL}$ (Uréia).

DMS Dunnett $=0,15 \mathrm{mg} / \mathrm{dL}$ (Creatinina). 
Sabe-se que a eliminação excessiva de uréia está relacionada a desordens renais, descompensação cardíaca, aumento no catabolismo protéico devido à alta ingestão de proteína, exercício intenso ${ }^{15}$, queimaduras e febres, choque hemorrágico, disenteria aguda. Em mamíferos, pela desaminação dos aminoácidos, há liberação de amônia, a qual é convertida, no fígado, em uréia pelo ciclo da uréia, sendo esta a principal forma de excreção de nitrogênio nestes animais. Em coelhos, por serem herbívoros, os microorganismos presentes no intestino grosso podem utilizar o amoníaco e a uréia e promover a atividade proteolítica. A população de microorganismos do ceco e cólon pode hidrolisar a uréia e a amônia como fonte de nitrogênio. Nesta espécie a principal forma de excreção de nitrogênio é amônia ${ }^{16}$.

Com referência à creatinina, a bixina foi a que mais reduziu seus níveis $(12,88 \%$ ) (Tabela 2). Embora estes valores tenham sido alterados, os seus níveis continuam dentro da faixa de valores normais, a qual, para coelhos, é de 0,8 a $2,57 \mathrm{mg} / \mathrm{dL}$.

A creatinina do soro é predominantemente um produto endógeno do catabolismo de creatina do músculo. Ela é formada nos animais a partir da arginina, podendo acumular-se no músculo e é reservatório de grupos fosfatos. Seus níveis são alterados principalmente em insuficiência renal, obstrução urinária e injúria muscular severa. Suas concentrações podem ser aumentadas em insuficiência renal ou injúria muscular severa. Tanto a uréia como a creatinina servem para detectar modelos de danificações nos rins ${ }^{17}$.

Em relação ao ácido úrico, a bixina $\mathrm{e}$ norbixina reduziram mais os seus níveis (17,92\% ) (Tabela 3). 0 ácido úrico nos animais é formado pelo metabolismo das bases purínicas, sendo a guanina e adenina convertidas em xantina e hipoxantina, respectivamente. Estas, por ação da xantina oxidase, resultarão em ácido úrico. Alteração nos processos de eliminação do ácido úrico gera como conseqüência a gota, condição patológica resultante do acúmulo de uratos nas articulações (gota articular) e nos órgãos (gota visceral) e muito comum em mamíferos, aves e répteis. A sua redução pode ter ocorrido através da inibição da xantina oxidase, o que seria importante nos tratamentos de pacientes com o nível de ácido úrico elevado, como no caso da gota, leucemia, anemia hemolítica, mieloma múltiplo, entre outras doenças.

Os diversos tratamentos afetaram pouco os níveis de proteínas, fato importante, considerando que a maioria delas é sintetizada pelo fígado. Elas são o principal componente do tecido muscular, dos hormônios e das enzimas, e correspondem aos anticorpos, elementos de defesa orgânica do animal contra doenças ${ }^{18}$. Geralmente,

Tabela 3. Ácido úrico e proteínas (+ erro-padrão) de coelhos avaliados aos 28 dias.

\begin{tabular}{|c|c|c|c|c|c|c|}
\hline \multirow{2}{*}{ Grupos } & \multirow{2}{*}{ Ácido úrico $(\mathrm{mg} / \mathrm{dL})$} & \multicolumn{2}{|c|}{ \% de variação } & \multirow{2}{*}{ Proteínas (mg/dL) } & \multicolumn{2}{|c|}{ \% de variação } \\
\hline & & Ração & Ração + CAC & & Ração & Ração + CAC \\
\hline 1 - Ração (R) & $0,73 \pm 0,19$ & - & - & $57,87 \pm 1,19$ & - & - \\
\hline $2-\mathrm{R}+$ Colesterol + Ácido cólico (CAC) & $1,06 \pm 0,06$ & - & - & $59,75 \pm 1,52$ & - & - \\
\hline $3-C A C+$ bixina & $0,87 \pm 0,13 a$ & 19,18 & $-17,92$ & $57,92 \pm 0,98 b$ & 0,09 & $-3,06$ \\
\hline $4-C A C+$ quercetina & $1,15 \pm 0,05 a$ & $57,63^{*}$ & $-8,49$ & $63,70 \pm 2,02 a$ & $10,07^{*}$ & $6,61^{*}$ \\
\hline 5 - CAC + bixina + quercetina & $0,88 \pm 0,14 a$ & 20,55 & $-16,98$ & $58,22 \pm 0,88 a b$ & 0,60 & $-2,56$ \\
\hline $6-C A C+$ norbixina & $0,87 \pm 0,09 a$ & 19,18 & $-17,92$ & $61,47 \pm 1,42 a b$ & $6,22 *$ & 2,88 \\
\hline
\end{tabular}

Médias seguidas de mesma letra minúscula não diferem entre si pelo teste de Tukey $(p>0,05)$.

${ }^{(*)}$ Estatisticamente diferente dos grupos controle pelo teste de Dunnett $(p<0,05)$.

DMS Dunnett $=0,32 \mathrm{mg} / \mathrm{dL}$ (Ácido Úrico).

DMS Dunnett $=3,55 \mathrm{mg} / \mathrm{dL}$ (Proteínas). 
reduções nos níveis plasmáticos das proteínas totais estão associadas com doenças renais ou hepáticas. A deficiência delas provoca crescimento retardado, redução na eficiência de utilização dos alimentos, queda na resistência a doenças, sendo a metionina e a lisina os dois aminoácidos mais importantes presentes nas proteínas dos coelhos ${ }^{18}$.

Flavonóides possuem efeitos sobre diversas proteínas, tais como fosfoinositídeo quinase 3 (PK3) e proteína quinase c (PKC), que estão sendo consideradas com papel chave em muitas respostas celulares, incluindo a multiplicação celular, apoptose e transformações. Eles podem ainda bloquear isoformas de PI3-kinase e PKc em respostas celulares ${ }^{19}$.

Proteínas como a albumina podem ser reduzidas em situações nas quais ocorra deficiência de magnésio, levando a processos inflamatórios. Diversas alterações na bioquímica do soro e plasma têm sido evidenciadas em animais deficientes em magnésio. Esta deficiência pode levar a hipoalbuminemia. No entanto, de acordo com pesquisa nesta área, a síntese de albumina e proteínas totais não é afetada no fígado pela deficiência desse mineral. Segundo sugerem os pesquisadores, a capacidade do fígado

Tabela 4. Cálcio, Aspartato aminotransferase e Alanina aminotrasferase ( \pm erro-padrão) de coelhos avaliados aos 28 dias.

\begin{tabular}{lccc}
\hline \multirow{2}{*}{ Grupos } & Cálcio $(\mathrm{mg} / \mathrm{dL})$ & \multicolumn{2}{c}{$\%$ de variação } \\
\cline { 3 - 3 } & & Ração & Ração + CAC \\
\hline 1 - Ração (R) & $13,65 \pm 0,39$ & - & - \\
2 - R + Colesterol + Ácido cólico (CAC) & $13,77 \pm 0,40$ & 2,20 & 1,31 \\
$3-$ CAC + bixina & $13,95 \pm 0,30 a$ & 1,47 & 0,58 \\
$4-$ CAC + quercetina & $13,85 \pm 0,73 a$ & $-4,32$ & $-5,16$ \\
$5-$ CAC + bixina + quercetina & $13,06 \pm 0,36 a$ & 4,91 & 3,99 \\
6 - CAC + norbixina & $14,32 \pm 0,31 a$ & & \\
\hline
\end{tabular}

\begin{tabular}{lccc}
\hline & & \multicolumn{2}{c}{$\%$ de variação } \\
\hline Grupos & AST (UI) & Ração & Ração + CAC \\
\hline - Ração (R) & $31,00 \pm 3,79$ & - & - \\
$2-$ R + Colesterol + Ácido cólico (CAC) & $69,80 \pm 15,74$ & - & $-42,22^{*}$ \\
$3-$ CAC + bixina & $40,33 \pm 14,78 a$ & 30,10 & $-41,98^{*}$ \\
$4-$ CAC + quercetina & $40,50 \pm 4,67 a$ & 30,65 & $-57,88^{*}$ \\
$5-$ CAC + bixina + quercetina & $29,40 \pm 3,87 a$ & $-5,16$ & $-56,55^{*}$ \\
6 - CAC + norbixina & $30,33 \pm 6,62 a$ & $-2,16$ & \\
\hline
\end{tabular}

\begin{tabular}{lccc}
\hline \multirow{2}{*}{ Grupos } & AST (UI) & \multicolumn{2}{c}{ \% de variação } \\
\hline 1 - Ração (R) & & Ração & Ração + CAC \\
2 - R + Colesterol + Ácido cólico (CAC) & $58,60 \pm 7,99$ & - & - \\
$3-$ CAC + bixina & $65,97 \pm 14,19$ & - & $-45,43 *$ \\
$4-$ CAC + quercetina & $36,00 \pm 3,62 a$ & $-38,57$ & $-23,60$ \\
$5-$ CAC + bixina + quercetina & $50,40 \pm 7,22 a$ & $-13,99$ & $-12,38$ \\
$6-$ CAC + norbixina & $57,80 \pm 9,64 a$ & $-1,37$ & $-12,34$ \\
\hline
\end{tabular}

Médias seguidas de mesma letra minúscula não diferem entre si pelo teste de Tukey $(p>0,05)$.

${ }^{(*)}$ Estatisticamente diferente dos grupos controle pelo teste de Dunnett $(p<0,05)$.

DMS Dunnett $=1,11 \mathrm{mg} / \mathrm{dL}$ (Cálcio).

DMS Dunnett $=23,73$ UI (AST).

DMS Dunnett $=24,04$ UI (ALT). 
de sintetizar albumina é superada e a hipoalbuminemia pode ser decorrente também do imenso catabolismo de proteínas que pode ocorrer na fase inflamatória. Muitos são os fatores que podem alterar os níveis de proteínas no plasma, mas os efeitos antiinflamatórios de flavonóides podem minimizar esses problemas ${ }^{20}$.

Todos os tratamentos aumentaram os níveis de cálcio, com exceção da associação bixina + quercetina, que os reduziu em 5,16\% (Tabela 4). Todas as concentrações, no entanto, se mantiveram dentro das variações normais em coelhos, as quais se situam entre 5,84 e $14,4 \mathrm{mg} / \mathrm{dL}$. O cálcio exerce várias funções no organismo: participa do metabolismo ósseo, influi no transporte de membranas celulares, afeta a transferência dos íons através das organelas, facilita a liberação dos neurotransmissores, atua na liberação e ativação de enzimas, entre outras. Os seus níveis são alterados principalmente em hiperparatireoidismo, hipervitaminose D, transplantes de rins, neoplasias, síndrome nefrótica, pancreatite aguda e também pelo uso de diuréticos.

0 tratamento com bixina + quercetina reduziu a concentração da atividade AST em 57,88\% (maior redução) e a ação dessa enzima se elevou em animais hiperlipidêmicos (Grupo 2). Os valores normais de atividade dessa enzima foram de $31 \mathrm{UI} / \mathrm{L}$ (Tabela 4). A AST catalisa a reação do ácido oxaloacético + acido glutâmico para produzir ácido $\alpha$-cetoglutárico + ácido aspártico. As variações na atividade dessa enzima podem ocorrer em hepatites infecciosas, hepato patias crônicas, icterícias, infarto do miocárdio, onde estas se elevam bastante.

A bixina apresentou a maior redução $(45,43 \%)$ na concentração de Alanina aminotransferase (ALT) (Tabela 4). Esta enzima também é responsável por reações de transaminação. Em coelhos seus valores normais foram da ordem de 58,60UI/L. Os níveis da ALT são elevados em hepatites e icterícias e a sua variação é menor que a da AST nos infartos do miocárdio.
A avaliação dos parâmetros sanguíneos demonstra que os compostos testados não foram considerados tóxicos para fígado e rim.

Outros pesquisadores, analisando a hepatotoxidade de flavonóides em culturas de hepatócitos de ratos, observaram que esses compostos não apresentaram efeitos tóxicos. Essa pesquisa foi avaliada pela liberação de lactato desidrogenase, inibição da respiração mitocondrial e desacoplamento da fosforilação oxidativa. Os flavonóides cítricos naringenina e hesperetina têm sido destacados por inibir a proliferação de receptores de estrogênio MDA-MB-235 e receptores de estrogênios positivos de células cancerígenas M CF-7. Portanto, esses estudos vêm comprovando efeitos benéficos dos flavonóidese a sua não-toxidade ${ }^{21}$

\section{O N C L USÃ O}

Os resultados obtidos nas condições experimentais estabelecidas neste trabalho mostram que as substâncias testadas reduziram os níveis dos parâmetros elevados pelo colesterol e ácido cólico, quais sejam: uréia, creatinina, ácido úrico, proteínas totais, cálcio, aspartato aminotransferase e alanina aminotransferase, conforme foi determinado pela análise dos constituintes sangüíneos de coelhos hiperlipidêmicos quando comparados ao grupo controle. A determinação desses dados permite avaliar se os compostos testados provocam alteração no metabolismo de aminoácidos, proteínas, ácidos nucléicos ou minerais. De acordo com a análise da ação terapêutica realizada no presente trabalho, a quercetina, bixina e norbixina não apresentaram efeitos deletérios, em relação aos parâmetros avaliados, evidenciando não ser possível demonstrar, somente com esse estudo, a inocuidade destes compostos. Outros testes devem ser feitos em espécies não roedoras que possuem metabolismo diferente. 


\section{A GRADECIMENTOS}

Os autores expressam seus agradecimentos à FAPEM IG - Fundação de Amparo à Pesquisa de Minas Gerais e ao CNPq - Conselho Nacional de Pesquisas pelo apoio financeiro e pela bolsa de pesquisas.

\section{RE FERÊ N C I A S}

1. Tierney JR LM, McPhee SJ, Papadakis MA. Diagnóstico e tratamento 2001: um livro médico. São Paulo: Atheneu; 2001. p.1161-73.

2. Kuhlman MK, Horsch E, Burkaardt G. Reduction of cisplatin toxicity in cultured renal tubular cells by the bioflavonoid quercetin. Arch Toxicol 1998; 72:536-40.

3. Youdim KA, McDonald J, Kahr W, Joseph JA. Potential role of dietary flavonoids in reducing microvascular endothelium vulnerability to oxidative and inflammatory insults. J Nutr Biochem 2002; 13:282-88.

4. Schamm DD, German JB. Pontential effects of flavonoids on the etiology of vascular disease. J Nutr Biochem 1998; 9:560-66.

5. Luna D, Rodrigues OM, Rada M, Mendez J. Actividad biológica de flavonoides. Analis do $4 \underline{0}$ Simpósio Internacional de Química de Productos Naturales y sus aplicaciones 1996. p.134-135.

6. Mascolo N, Borreli F, Capsso R, Capasso F, Carlo GG, Izzo AA, et al. Natural Products and cardiovascular disturbances. Phytother Res 1998; 12:121-23.

7. Katan MB, Hollman PCH. Dietary flavonoids: intake, health effects and bioavailability. Food Chem Toxicol 1999; 37:927-42.

8. Cai Q, Ranhn RO, Zhang R. Dietary flavonoids, quercetin, luteolin and genistein reduce oxidative DNA damage and lipid peroxidation and quench free radicals. Cancer Letters 1999; 119:99-107.

9. Lima LRP, Oliveira TT, Nagem TJ, Pinto AS, Stringheta $P C$, Tinoco ALA, et al. Bixina, norbixina e quercetina e seus efeitos no metabolismo lipídico de coelhos. Braz J Vet Res Anim Sci 2001; 38(4)1-9.

10. Oliveira TT, Nagem TJ, Pereira WL, Pinto AS, Stringheta PC. Hypolipidemic and synergic effects of naringinin, chrolophyl and monascus in rats. (Ratus norvicus). Aliment Nutr, 2001; 12:95-102.

11. Fontana JD, Mendes SV, Persicke DS, Peracetta LF, Passos M. 2000. Carotenóides. Biotecnol Ciênc Desenvol 2000; (13):40-5.

12. Zhao W, Han Y, Zhao B, Hirota S, Hou J, Xin W. Effect of carotenoids on the respiratory burst of rat peritoneal macrophages. Biochemical Biophys Acta 1998; 138:77-88.

13. Saija A, Rapisarda A, Tomaino A, Trombeta D. Flavonoid interactions with biomembranes. Phytother Res 1996; 10:S132-S134.

14. Lima LRP, Oliveira TT, Oliveira M GA, Nagem TJ, Pinto ASP, Gomes SM , et al. Determinação da atividade de lipase na presença de Morina, Naringenina, Naringina e Rutina. Cienc Agrotec Lavras, 1999; 23:626-31.

15. Fox RR. The rabbit. In: The clinical chemistry of laboratory animals. Loeb WF, Quimby FW, editors New York: Pergamon; 1989. p.41-6.

16. Cheeke PR. Alimentación y nutrición del conejo. Orlando, Flórida: Academic Press; 1987.

17. Peralta J, Amancio OMS. A creatina como suplemento ergogênico para atletas. Rev Nutr 2002; 15(1):83-93.

18. M ello HV, Silva JF. A criação de coelhos. 2.ed. Rio de Janeiro: Publicações Globo Rural; 1988.

19. Paraystre L, M anenti S, Gratacap M, Tuliez J, Chap $H$, Payrastre $B$. Flavonoids and the inhibition onPKC and PI3-kinase. Gen Pharmacol 1999; 32:279-86.

20. Nassir F, Wioletta Z, Bayle D, Gueux E, Rayssiguier $Y$, Mazur A. Hypoalbuminaemia in acute phase response is not related to depressed albumin synthesis: experimental evidence in magnesium deficient rat. Nutr Res 2000; 22:489-96.

21. Miranda CL, Stevens JF, Helmirich A, Henderson MC, Rodriguez RJ, Yang YH, et al. Antiproliferative and cytotoxic effects of prenylated flavonoids from hops (humulus lupulus) in human cancer cell lines. Food Chem Toxicol 1999; 37(4):271-85.

Recebido para publicação em 18 de julho de 2001 e aceito em 16 de dezembro de 2002. 